\title{
Current Status of Antibiograms of Listeria ivanovii and Enterobacter cloacae Isolated from Ready-To-Eat Foods in Alice, South Africa
}

\author{
Mirriam E. Nyenje ${ }^{1}$, Nicoline F. Tanih ${ }^{1}$, Ezekiel Green ${ }^{1}$ and Roland N. Ndip ${ }^{1,2, *}$ \\ 1 Department of Biochemistry and Microbiology, Faculty of Science and Agriculture, University of \\ Fort Hare, PMB X1314, Alice 5700, South Africa; E-Mails:nyenjem@yahoo.com (M.E.N.); \\ nicofriline@yahoo.com (N.F.T.); egreen@ufh.ac.za (E.G.) \\ 2 Department of Microbiology and Parasitology, Faculty of Science, University of Buea, \\ P.O. Box 63, Buea, Cameroon \\ * Author to whom correspondence should be addressed; E-Mail: rndip@ufh.ac.za; \\ Tel.: +27-782-696-191; Fax: +27-866-24-759.
}

Received: 23 July 2012; in revised form: 16 August 2012 / Accepted: 22 August 2012 /

Published: 29 August 2012

Abstract: This study assessed the antimicrobial susceptibility of 51 Listeria ivanovii and 33 Enterobacter cloacae strains isolated from various ready-to-eat foods sold in Alice, South Africa. Isolates were identified using standard microbiological tests and further confirmed using API 20E and API Listeria kits. The disc diffusion technique was used to screen for antimicrobial susceptibility against 15 antimicrobials; minimum inhibitory concentration of five antibiotics was determined by the broth dilution method. All the strains of E. cloacae (100\%) and $96 \%$ of L. ivanovii isolates were resistant to at least four or more of the antibiotics; nineteen antibiotypes were obtained based on the antibiotics used in the study. Antibiotype A5: $A^{R} P^{R} V^{R} E^{R} A P^{R}$ was predominant in both L. ivanovii (23.5\%) and E. cloacae (57.5\%) isolates. Marked susceptibility of Listeria ivanovii was observed against chloramphenicol, ciprofloxacin, streptomycin and trimethoprim/sulfamethoxazole $(100 \%)$ each while E. cloacae registered $100 \%$ susceptibility to ciprofloxacin only. Various percentages of susceptibility was reported to chloramphenicol and gentamicin (91\%) each, nalidixic acid (97\%) and streptomycin (94\%). The $\mathrm{MIC}_{90}$ ranged from $0.004-7.5 \mu \mathrm{g} / \mathrm{mL}$ with E. cloacae being the most susceptible organism. The study demonstrated the presence of multi-resistant strains of 
bacteria in ready-to-eat-foods and speculates that these foods could serve as important vehicles transmitting multi-resistant bacteria to humans.

Keywords: foodborne pathogens; Listeria ivanovii; Enterobacter cloacae; antibiotic resistance; minimum inhibitory concentration; South Africa

\section{Introduction}

Antimicrobial resistance is currently the greatest challenge worldwide. It decreases the effectiveness of drugs that decrease morbidity and mortality associated with serious and life-threatening infections and thus, compromising human health [1]. Food contamination with antimicrobial resistant bacteria can be a major threat to public health, as the antibiotic resistance determinants can be transferred to other bacteria of human clinical significance. Since the last decade, the prevalence of antimicrobial resistance among foodborne pathogens has increased [2,3], possibly as a result of selection pressure created by the use of antimicrobials in animal health [4].

Although foodborne diseases represent an important health problem, the international impact of foodborne illness is difficult to estimate as large numbers of illnesses remain underreported [5]. On the other hand, these illnesses are sometimes indistinguishable from other diseases because they share common symptoms. Therefore, it is generally accepted in the scientific community, that the true incidence of foodborne diseases is unknown [6]. However, in the USA, foodborne illnesses are estimated to be responsible for some 76 million cases and 3,000 deaths each year [7], whereas in the United Kingdom, foodborne diseases are estimated at 1.7 million per year [8]. Several devastating outbreaks of foodborne diseases have been reported on the African continent, including acute aflatoxicosis in Kenya, which resulted in 317 cases and 125 deaths [9]. Although cholera is preventable and treatable, Africa continues to be plagued with annual outbreaks. In 2005, a total of 131,943 cases and 2,272 deaths were reported to the World Health Organization with Africa accounting for 58\% of the global incidence [10]. In 2008, Zimbabwe, reported 98,424 cases and 4,276 deaths [11].

The most common clinical presentation of foodborne diseases takes the form of gastrointestinal symptoms which are generally mild and self-limiting, hence no antimicrobial therapy is required. However, therapy may be life-saving in patients with underlying illness and those with prolonged febrile course of illness in whom invasive illness is suspected [12]. Antimicrobial resistance in some enteric pathogens, for example Listeria monocytogenes has been documented, which has negatively affected the management of serious infections caused by these organisms [13].

Listeria species are ubiquitous, Gram-positive bacteria that possess characteristics such as the ability to form biofilms, growth at low temperatures, and tolerance of osmotic stress. These factors inevitably contribute to its persistence in and adaptation to the environment. L. monocytogenes and L. ivanovii are reported to be the causative agents of listeriosis in both humans and animals, with the latter rarely occurring in humans [3]. However, Guillet et al. [14] related the few cases of L. ivanovii infection to sporadic occurrence of the organism in nature, as the organism is isolated occasionally from animals or environmental sources including food. Furthermore, this organism has been 
increasingly isolated in food and different environments in some areas [15-18]. The bacterium was the most prevalent in wastewater and treated final effluents in the same study area of the present study [16]; similarly it was common in cooked food samples in the area [18] suggesting its prevalence in our environment. Listeriosis has been associated with mortality rates of up to $30 \%$ in infants and in patients with underlying diseases [19]. The main route of transmission is through consumption of contaminated food. The bacteria can also be acquired by the foetus from its infected mother via the placenta [3]. Listeriosis in immunocompetent adults develops as gastroenteritis which is normally self-limiting, however in immunocompromised individuals, the infection can manifest as septicaemia or meningoencephalitis whereas perinatal infections can lead to abortion, or sepsis and meningitis in the neonates [20].

The first choice of treatment for listeriosis is a $\beta$-lactam antibiotic (e.g., penicillin or ampicillin), alone or in combination with an aminoglycoside (e.g., gentamicin). The association of trimethoprim with a sulfonamide, such as sulfamethoxazole in co-trimoxazole, is considered to be a second choice therapy $[19,21,22]$. However, Listeria strains resistant to penicillin, ampicillin, erythromycin, streptomycin and tetracycline have been reported which dictates judicious use of these drugs [19,23,24].

E. cloacae occur in water, sewage, soil, food, and as commensal microflora in the intestinal tracts of humans and animals. They are frequently isolated from clinical and food samples as opportunistic pathogens [25]. These organisms are important nosocomial pathogens responsible for local and systemic infections in humans [26]. Outbreaks of E. cloacae have been reported in South Africa [27,28] In 1998, an outbreak in the neonatal intensive care unit of a Gauteng hospital was reported and the investigation revealed that six of the isolates were from environmental sources, three from blood cultures of patients and one from the hands of a staff member [27]. Resistant strains among clinical isolates of these organisms have also been documented in hospitalized patients in Pretoria and Johannesberg [28]. A wide variety of drugs are currently used in the treatment of infections caused by this organism. Such antibiotics include aminoglycosides, trimethoprim-sulfamethoxazole, fluoroquinolones and carbapenems. However, there are reports of an increasing prevalence of antimicrobial-resistant Enterobacteriaceae, not only pathogenic but also commensal bacteria, suggestive that the community can act as a reservoir, and food can contribute to the spread of these resistant strains [29]. E. cloacae have been reported to be resistant to ampicillin, erythromycin, rifampicin and sulfamethoxazole [30]. Some strains have also been found to produce extended-spectrum beta-lactamase and AmpC, conferring resistance to both third and fourth generation cephalosporins [31].

Emergence of antimicrobial resistance bacteria has become a serious problem worldwide. While much of the resistance observed in human medicine is attributed to inappropriate use of antibiotics in humans, there is increasing evidence that antimicrobial use in animals selects for resistant foodborne pathogens that may be transmitted to humans as food contaminants $[1,32]$. Therefore, the present study was carried out to determine the antimicrobial susceptibility profiles of L. ivanovii and E. cloacae isolated from ready-to-eat foods from Alice, South Africa, in an effort to assess the risks these foods may pose to the community.

\section{Results and Discussion}

\subsection{Antimicrobial Patterns}

All L. ivanovii (51) isolates were resistant (total) to vancomycin, penicillin G and erythromycin, but were sensitive to chloramphenicol, ciprofloxacin, streptomycin and sulfamethoxazole/trimethoprim. Of 
the 51 isolates, $98 \%$ were susceptible to nalidixic acid and gentamicin; while susceptibilities of $82 \%$ and 55\% were reported to trimethoprim and tetracycline respectively; the rest showed either intermediate or total resistance to these antibiotics. Ciprofloxacin was the most active drug. All E. cloacae strains $(100 \%)$ were susceptible to ciprofloxacin while various degrees of susceptibility to nalidixic acid 32 (97\%), streptomycin 31 (94\%), gentamicin and chloramphenicol 30 (91\%) each, were observed. However, the isolates showed marked resistance (100\%) to amoxicillin, penicillin G, vancomycin and erythromycin, while $26(79 \%)$ and $19(58 \%)$ of the isolates were resistant to ampicillin and tetracycline respectively (Table 1). The results of this study corroborate other findings $[22,32,33]$. However these findings are also contrary to those of Odjadjare et al. [16] who reported moderate sensitivity to ciprofloxacin (91\%), chloramphenicol (87\%) and streptomycin (65\%) by strains recovered from waste water effluents in the same study area of the current study. This discrepancy may be due to the different sample sources of the isolates which may impact on their adaptation and response to different chemicals and antimicrobial agents. Previous studies on the antimicrobial susceptibility profiles of Listeria species have focused mainly on L. monocytogenes with a dearth of information in the literature on antibiotic susceptibility profiles for L. ivanovii. However, this animal pathogen is equally important to man as it has been isolated from infected humans, indicating pathogenic potential for humans [14].

Table 1. Antimicrobial susceptibility profile of L. ivanovii and E. cloacae isolated from ready-to-eat foods.

\begin{tabular}{llll}
\hline \multirow{2}{*}{ Antibiotic } & \multicolumn{3}{c}{ Number (\%) } \\
\cline { 2 - 4 } & \multicolumn{3}{c}{ L. ivanovii (n = 51) } \\
\cline { 2 - 4 } & $\mathrm{S}$ & $\mathrm{I}$ & $\mathrm{R}$ \\
\hline Chloramphenicol $(30 \mu \mathrm{g})$ & $51(100)$ & $0(0)$ & $0(0)$ \\
Kanamycin $(30 \mu \mathrm{g})$ & $21(39)$ & $19(37)$ & $11(22)$ \\
Amoxacillin $(20 \mu \mathrm{g})$ & $3(6)$ & $0(0)$ & $48(94)$ \\
Penicillin G $(10 \mathrm{units})$ & $0(0)$ & $0(0)$ & $51(100)$ \\
Vancomycin $(30 \mu \mathrm{g})$ & $0(0)$ & $0(0)$ & $51(100)$ \\
Ciprofloxacin $(5 \mu \mathrm{g})$ & $51(100)$ & $0(0)$ & $0(0)$ \\
Streptomycin $(10 \mu \mathrm{g})$ & $51(100)$ & $0(0)$ & $0(0)$ \\
Trimeth/Sulfamethoxazole $(1.25 \mu \mathrm{g})$ & $51(100)$ & $0(0)$ & $0(0)$ \\
Nalidixic acid $(30 \mu \mathrm{g})$ & $50(98)$ & $1(2)$ & $0(0)$ \\
Trimethoprim $(5 \mu \mathrm{g})$ & $42(82)$ & $4(8)$ & $5(10)$ \\
Erythromycin $(15 \mu \mathrm{g})$ & $0(0)$ & $0(0)$ & $51(100)$ \\
Neomycin $(30 \mu \mathrm{g})$ & $20(39)$ & $24(47)$ & $7(14)$ \\
Tetracycline $(30 \mu \mathrm{g})$ & $28(55)$ & $0(0)$ & $23(45)$ \\
Ampicillin $(10 \mu \mathrm{g})$ & $23(45)$ & $5(10)$ & $23(45)$ \\
Gentamicin $(10 \mu \mathrm{g})$ & $50(98)$ & $1(2)$ & $0(0)$ \\
\hline
\end{tabular}


Table 1. Cont.

\begin{tabular}{llll}
\hline \multirow{2}{*}{ Antibiotic } & \multicolumn{3}{c}{ Enterobacter cloacae (n = 33) } \\
\cline { 2 - 4 } & $\mathrm{S}$ & $\mathrm{I}$ & $\mathrm{R}$ \\
\hline Chloramphenicol $(30 \mu \mathrm{g})$ & $30(91)$ & $2(6)$ & $1(3)$ \\
Kanamycin $(30 \mu \mathrm{g})$ & $27(82)$ & $3(9)$ & $3(9)$ \\
Amoxacillin $(20 \mu \mathrm{g})$ & $0(0)$ & $0(0)$ & $33(100)$ \\
Penicillin G $(10 \mathrm{units})$ & $0(0)$ & $0(0)$ & $33(100)$ \\
Vancomycin $(30 \mu \mathrm{g})$ & $0(0)$ & $0(0)$ & $33(100)$ \\
Ciprofloxacin $(5 \mu \mathrm{g})$ & $33(100)$ & $0(0)$ & $0(0)$ \\
Streptomycin $(10 \mu \mathrm{g})$ & $31(94)$ & $2(6)$ & $0(0)$ \\
Trimeth/Sulfamethoxazole $(1.25 \mu \mathrm{g})$ & $26(79)$ & $0(0)$ & $7(21)$ \\
Nalidixic acid $(30 \mu \mathrm{g})$ & $32(97)$ & $1(3)$ & $0(0)$ \\
Trimethoprim $(5 \mu \mathrm{g})$ & $26(78)$ & $0(0)$ & $7(21)$ \\
Erythromycin $(15 \mu \mathrm{g})$ & $0(0)$ & $0(0)$ & $33(100)$ \\
Neomycin $(30 \mu \mathrm{g})$ & $15(45)$ & $13(39)$ & $5(15)$ \\
Tetracycline $(30 \mu \mathrm{g})$ & $14(42)$ & $0(0)$ & $19(58)$ \\
Ampicillin $(10 \mu \mathrm{g})$ & $0(0)$ & $7(21)$ & $26(79)$ \\
Gentamicin $(10 \mu \mathrm{g})$ & $30(91)$ & $1(3)$ & $2(6)$ \\
\hline
\end{tabular}

S, sensitive; I, intermediate; R, resistant.

Multidrug resistance was a common phenomenon observed in all the 51 (100\%) L. ivanovii and $33(100 \%)$ E. cloacae isolates. Nineteen antibiotic resistance patterns were obtained (Table 2). Antibiotype A5: $A^{R} P^{R} V^{R} E^{R} A^{R}$ (amoxicillin, penicillin $G$, vancomycin, erythromycin, ampicillin) was predominant in both L. ivanovii (23.5\%) and E. cloacae (57.5\%) isolates, followed by A3: $A^{R} P^{R} V^{R} E^{R}$ (amoxicillin, penicillin $G$, vancomycin, erythromycin) which was obtained from seven $(21.2 \%)$ of E. cloacae and $11(22.5 \%)$ of L. ivanovii. The least resistant patterns for E. cloacae (3\%) were demonstrated by A15 and A19 while for L. ivanovii (1.9\%) A2, A4, A7, A11 and A12 respectively demonstrated the same pattern.

The results indicated alarming multi-resistance frequencies to at least four or more of the test antibiotics. This is of major concern to the public as these foods may act as reservoir of resistant strains that can be transmitted to humans upon ingestion of the contaminated food. Similar patterns of resistance have been reported by other authors [24,30,32]. Srinivasan et al. [24] found that all L. monocytogenes strains isolated from a dairy farm environment were resistant to ampicillin and rifampicin, and some to tetracycline, penicillin and chloramphenicol. Furthermore, Haryani et al. [30] in their study observed that all E. cloacae strains studied were resistant to six or more antibiotics.

The results suggest that incidence of antibiotic resistance in L. ivanovii is relatively high. It is of great concern that the range of antibiotics to which resistance has been acquired is wide and the expanding range now includes a number of antibiotics used to treat listeriosis (penicillin, vancomycin, erythromycin and ampicillin). This may have future implications for the effective treatment of listeriosis if these resistant strains could be transferred to humans. Interestingly, the study reported high susceptibility of strains to gentamicin (98\%) and trimethoprim/sulfamethoxazole (100\%), drugs which are considered as second choice therapy [22]. These findings are in agreement with other reports $[22,24,34]$. 
Table 2. Antibiotypes of E. cloacae and L. ivanovii.

\begin{tabular}{|c|c|c|c|}
\hline \multirow{2}{*}{ No } & \multirow{2}{*}{ Antibiotype } & \multicolumn{2}{|c|}{ Number (\%) } \\
\hline & & E. cloacae & L. ivanovii \\
\hline A1 & $P G^{R} V A^{R} E^{R}$ & $0(0)$ & $3(5.9)$ \\
\hline $\mathrm{A} 2$ & $P G^{R} V A^{R} E^{R} T^{R}$ & $0(0)$ & $1(1.9)$ \\
\hline $\mathrm{A} 3$ & $A^{R} P G^{R} V A^{R} E^{R}$ & $7(21.2)$ & $11(22.5)$ \\
\hline A4 & $\mathrm{K}^{\mathrm{R}} \mathrm{A}^{\mathrm{R}} \mathrm{PG}^{\mathrm{R}} \mathrm{VA}^{\mathrm{R}} \mathrm{E}^{\mathrm{R}}$ & $0(0)$ & $1(1.9)$ \\
\hline A5 & $A^{R} P G^{R} V A^{R} E^{R} A P^{R}$ & $19(57.5)$ & $12(23.5)$ \\
\hline A6 & $A^{R} P G^{R} V A^{R} E^{R} T^{R}$ & $0(0)$ & $5(9.8)$ \\
\hline A7 & $\mathrm{K}^{\mathrm{R}} \mathrm{A}^{\mathrm{R}} \mathrm{PG}^{\mathrm{R}} \mathrm{VA}^{\mathrm{R}} \mathrm{E}^{\mathrm{R}} \mathrm{AP}^{\mathrm{R}}$ & $0(0)$ & $1(1.9)$ \\
\hline A8 & $K^{R} A^{R} P G^{R} V A^{R} E^{R} T^{R}$ & $0(0)$ & $3(5.9)$ \\
\hline A9 & $A^{R} P G^{R} V A^{R} E^{R} T^{R} A P^{R}$ & $0(0)$ & $5(9.8)$ \\
\hline A10 & $A^{R} P G^{R} V A^{R} E^{R} N E^{R} T^{R}$ & $0(0)$ & $2(3.9)$ \\
\hline A11 & $A^{R} P G^{R} V A^{R} W^{R} E^{R} T^{R} A P^{R}$ & $0(0)$ & $1(1.9)$ \\
\hline A12 & $K^{R} A^{R} P G^{R} V A^{R} E^{R} N E^{R} A P^{R}$ & $0(0)$ & $1(1.9)$ \\
\hline A13 & $K^{\mathrm{R}} A^{\mathrm{R}} P G^{\mathrm{R}} V A^{\mathrm{R}} E^{\mathrm{R}} T^{\mathrm{R}} A P^{\mathrm{R}}$ & $0(0)$ & $2(3.9)$ \\
\hline A14 & $K^{R} A^{R} P G^{R} V A^{R} E^{R} N E^{R} T^{R}$ & $0(0)$ & $2(3.9)$ \\
\hline A15 & $A^{R} P G^{R} V A^{R} W^{R} E^{R} T^{R} A P^{R}$ & $1(3)$ & $0(0)$ \\
\hline A16 & $A^{R} P G^{R} V A^{R} S X T^{R} W^{R} E^{R} T^{R} A P^{R}$ & $3(9)$ & $0(0)$ \\
\hline A17 & $K^{R} A^{R} P G^{R} V A^{R} W^{R} E^{R} N E^{R} T^{R} A P^{R}$ & $0(0)$ & $2(3.9)$ \\
\hline A18 & $K^{R} A^{R} P G^{R} V A^{R} S X T^{R} W^{R} E^{R} N E^{R} T^{R} A P^{R} G^{R}$ & $2(6)$ & $0(0)$ \\
\hline A19 & $C^{R} K^{R} A^{R} P G^{R} V A^{R} S X T^{R} W^{R} E^{R} N E^{R} T^{R} A^{R} G^{R}$ & $1(3)$ & $0(0)$ \\
\hline
\end{tabular}

$\mathrm{A}$, amoxicillin; C, chloramphenicol; K, kanamycin; $\mathrm{PG}$, penicillin $\mathrm{G}$; VA, vancomycin; SXT, trimethoprim/sulfamethoxazole; W, trimethoprim; E, erythromycin; NE, neomycin; T, tetracycline; AP, ampicillin; GM, gentamicin.

The increases in antibiotic resistance among Listeria spp. are in line with the general worldwide pattern of an increasing prevalence of antibiotic resistance, including multiple antibiotic resistances among many groups of bacteria. Multiple drug resistance in these organisms have been attributed to antimicrobial selective pressure and gene transfer mechanisms between and among Listeria species and close relatives of the bacteria such as Enterococcus, Streptococcus and Staphylococcus species [21,34].

The present study observed $100 \%$ resistance of E. cloacae to amoxicillin, penicillin, ampicillin and erythromycin, while for neomycin and tetracycline it was $45 \%$ and $42 \%$ respectively. The findings are in agreement with those of Haryani et al. [30], who observed 100\% resistance to ampicillin and erythromycin; however, their study demonstrated various degrees of resistance to streptomycin (85.71\%), ciprofloxacin and tetracycline $(42.86 \%)$ and trimethoprim $(28.57 \%)$ contrary to the findings of this study where ciprofloxacin recorded $100 \%$ sensitivity. Environmental factors as well as differing prescription practices may try to explain these discrepancies.

The emerging antibiotic resistance in the Enterobacteriaceae family is a significant problem that requires vigilance and intensified measures to control the further spread of resistance by these important Gram-negative pathogens. Worthy of note is the fact that most research has involved 
organisms that directly cause disease, focusing less on important contributions by commensal bacteria. Although these organisms generally do not cause disease in immunocompetent people, they can transfer resistance genes to other bacteria in the environment [31]. The European Community therefore recommended the monitoring of antimicrobial resistance in these organisms; E. cloacae is one of the few bacteria where monitoring in healthcare facilities is recommended [35].

There are reports on similarities in virulence factors between human and food isolates of Enterococcus spp., implying that food commensals may be an overlooked aspect of antibiotic resistance [36]. Several studies have tracked resistant zoonotic species using non-pathogenic E. coli as an indicator organism. DeFrancesco et al. [37] demonstrated that commensal E. coli had higher rates of resistance than pathogenic multi-drug resistant Salmonella from the same herds, suggesting that commensal bacteria could be used to survey the prevalence of antibiotic resistant bacteria. On the other hand, food animal reservoirs are an important source of antimicrobial resistance, even though it might be difficult to quantify the exact burden, compared with human use.

\subsection{Minimum Inhibitory Concentration (MIC90) Determination}

Of the five antimicrobials tested, E. cloacae isolates were more susceptible to ciprofloxacin with $\mathrm{MIC}_{90}$ ranging as low as $0.004-3.75 \mu \mathrm{g} / \mathrm{mL}$. The $\mathrm{MIC}_{90}$ of kanamycin, tetracycline, nalidixic acid and chloramphenicol ranged from $0.029-0.117 \mu \mathrm{g} / \mathrm{mL}, 0.029-3.75 \mu \mathrm{g} / \mathrm{mL}, 0.029-0.937 \mu \mathrm{g} / \mathrm{mL}$ and $0.058-0.937 \mu \mathrm{g} / \mathrm{mL}$ respectively (Table 3 ).

Table 3. Minimum inhibitory concentration $\left(\mathrm{MIC}_{90}\right)$ of different antibiotics against E. cloacae isolates.

\begin{tabular}{cccccc}
\hline Isolate no. & Cip & T & C & K & NA \\
\hline $1-E$ & 0.009 & 0.029 & 0.234 & 0.029 & 0.234 \\
$2-E$ & 0.019 & 0.468 & 0.468 & 0.058 & 0.234 \\
$4-E$ & 0.009 & 0.117 & 0.468 & 0.117 & 0.058 \\
$5-E$ & 0.625 & 3.75 & 0.937 & ND & 0.234 \\
$7-E$ & 0.004 & 0.117 & 0.234 & 0.117 & 0.117 \\
$09-2$ & 0.004 & 0.117 & 0.468 & 0.058 & 0.029 \\
$012-2$ & 0.156 & 0.468 & 0.468 & 0.029 & 0.234 \\
$052-2$ & 0.009 & 0.234 & 0.937 & 0.117 & 0.234 \\
$057-2$ & 0.009 & 0.117 & 0.468 & 0.117 & 0.058 \\
$067-2$ & 0.019 & 0.468 & 0.468 & 0.058 & 0.117 \\
$070-2$ & 0.004 & 0.117 & 0.937 & 0.058 & 0.234 \\
$073-2$ & 0.009 & 0.234 & 0.468 & 0.014 & 0.058 \\
$089-2$ & 0.009 & 0.117 & 0.058 & 0.029 & 0.468 \\
$103-1$ & 0.019 & 0.234 & 0.468 & 0.058 & 0.117 \\
$112-3$ & 0.004 & 0.058 & 0.937 & 0.117 & 0.117 \\
$224-3$ & 0.009 & 0.117 & 0.468 & 0.234 & 0.117 \\
$247-2$ & 0.019 & 0.117 & 0.637 & 0.234 & 0.468 \\
\hline
\end{tabular}


Table 3. Cont.

\begin{tabular}{cccccc}
\hline Isolate no. & Cip & T & C & K & NA \\
\hline $114-2$ & 0.009 & 0.117 & 0.058 & 0.117 & 0.468 \\
$119-2$ & 0.019 & 0.117 & 0.468 & 0.058 & 0.029 \\
$164-1$ & 0.004 & 0.029 & 0.468 & 0.058 & 0.468 \\
$171-1$ & 0.625 & ND & 0.468 & ND & 0.937 \\
$172-1$ & 0.625 & ND & 0.937 & ND & 0.234 \\
$177-1$ & 0.019 & 0.937 & 0.468 & 0.058 & 0.117 \\
$194-3$ & 0.009 & 0.117 & 0.234 & 0.029 & 0.234 \\
$198-2$ & 0.004 & 0.468 & 0.468 & 0.058 & 0.234 \\
$205-3$ & 0.004 & 0.117 & 0.937 & 0.117 & 0.029 \\
$208-2$ & 0.156 & 0.468 & 0.468 & 0.117 & 0.234 \\
$217-3$ & 0.312 & ND & 0.234 & 0.029 & 0.468 \\
$220-2$ & 0.009 & 0.468 & 0.234 & 0.029 & 0.234 \\
$221-2$ & 0.004 & 0.234 & 0.468 & 0.117 & 0.029 \\
$225-3$ & 0.009 & 0.234 & 0.937 & 0.117 & 0.117 \\
$235-2$ & 0.312 & ND & 0.468 & ND & 0.937 \\
$251-3$ & 0.156 & ND & 0.234 & 0.117 & 0.029 \\
\hline
\end{tabular}

Cip, ciprofloxacin; T, tetracycline; K, kanamycin; NA, nalidixic acid; C, chloramphenicol; ND, not determined.

On the other hand, the $\mathrm{MIC}_{90}$ for L. ivanovii isolates, ranged from $0.009-0.625 \mu \mathrm{g} / \mathrm{mL}$ for ciprofloxacin, 0.014-7.5 $\mu \mathrm{g} / \mathrm{mL}$ for tetracycline, $0.029-3.75 \mu \mathrm{g} / \mathrm{mL}$ for chloramphenicol, $0.058-7.5 \mu \mathrm{g} / \mathrm{mL}$ for kanamycin and $0.058-7.5 \mu \mathrm{g} / \mathrm{mL}$ for nalidixic acid (Table 4).

Table 4. Minimum inhibitory concentration $\left(\mathrm{MIC}_{90}\right)$ of different antibiotics against L. ivanovii isolates.

\begin{tabular}{llllll}
\hline Isolate no. & Cip & T & C & K & NA \\
\hline $61-2$ & 0.039 & 1.875 & 0.937 & 0.058 & 3.75 \\
$74-1$ & 0.312 & 0.937 & 0.468 & 0.117 & 7.5 \\
$99-2$ & 0.078 & 0.117 & 0.234 & 0.117 & 0.468 \\
$109-1$ & 0.009 & 0.058 & 0.468 & 3.75 & 0.117 \\
$117-2$ & 0.312 & 0.937 & 0.468 & 0.234 & 1.875 \\
$127-2$ & 0.019 & 0.117 & 1.875 & 0.117 & 0.468 \\
$155-2$ & 0.078 & 1.875 & 3.75 & 0.234 & 0.468 \\
$160-1$ & 0.625 & 0.234 & 0.468 & 0.117 & 1.875 \\
$188-2$ & 0.039 & 0.937 & 0.234 & 0.234 & 3.75 \\
$190-2$ & 0.039 & 0.937 & 0.937 & 0.117 & 0.937 \\
$192-2$ & 0.006 & 0.014 & 0.937 & 0.058 & 0.058 \\
$63-1$ & 0.312 & 0.937 & 0.234 & 0.468 & 1.875 \\
$196-1$ & 0.078 & 0.117 & 3.75 & 0.234 & 0.468 \\
$55-1$ & 0.009 & 1.875 & 0.468 & 3.75 & 1.875 \\
$164-1$ & 0.019 & 0.058 & 0.937 & 1.875 & 1.875 \\
$123-1$ & 0.156 & 0.058 & 0.468 & 0.234 & 0.468 \\
$73-1$ & 0.019 & 1.875 & 0.937 & 0.234 & 0.468 \\
$20-2$ & 0.078 & 1.875 & 0.937 & 0.117 & 3.75 \\
\hline
\end{tabular}


Table 4. Cont.

\begin{tabular}{|c|c|c|c|c|c|}
\hline Isolate no. & Cip & $\mathbf{T}$ & C & $\mathbf{K}$ & NA \\
\hline $93-2$ & 0.009 & 0.058 & 0.029 & 3.75 & 0.234 \\
\hline $159-1$ & 0.039 & 0.468 & 0.937 & 0.117 & 0.468 \\
\hline $195-1$ & 0.009 & 1.875 & 0.468 & 3.75 & 1.875 \\
\hline $119-2$ & 0.312 & 0.058 & 3.75 & 0.468 & 3.75 \\
\hline $118-2$ & 0.019 & 3.75 & 0.234 & 1.875 & 1.875 \\
\hline $58-2$ & 0.078 & 1.875 & 3.75 & 0.234 & 0.468 \\
\hline $111-1$ & 0.039 & 0.937 & 0.468 & 0.117 & 0.937 \\
\hline $01-2$ & 0.312 & 0.937 & 0.468 & 0.468 & 1.875 \\
\hline $03-2$ & 0.312 & 0.058 & 3.75 & 0.234 & 3.75 \\
\hline $04-2$ & 0.078 & 0.117 & 3.75 & 0.234 & 0.468 \\
\hline $08-2$ & ND & 0.117 & 0.468 & 0.468 & 3.75 \\
\hline $16-2$ & 0.156 & 0.937 & 0.937 & 0.234 & 7.5 \\
\hline $17-2$ & 0.156 & 0.058 & 0.468 & 0.234 & 0.468 \\
\hline $20-2$ & 0.039 & 0.937 & 0.937 & 0.234 & 3.75 \\
\hline $27-E$ & 0.039 & 0.117 & 0.937 & 0.937 & 0.468 \\
\hline $32-3$ & 0.009 & 0.234 & 3.75 & 0.234 & 0.937 \\
\hline $37-1$ & 0.625 & 0.117 & 0.468 & 0.468 & 0.937 \\
\hline $198-1$ & 0.312 & 0.117 & 3.7 & 0.234 & 3.75 \\
\hline $38-1$ & 0.156 & 0.234 & 0.468 & 0.117 & 1.875 \\
\hline $39-1$ & 0.039 & 0.937 & 0.937 & 0.234 & 0.468 \\
\hline $41-1$ & 0.019 & 0.058 & 0.937 & 0.937 & 1.875 \\
\hline $42-3$ & 0.009 & 1.875 & 0.234 & 3.75 & 1.875 \\
\hline $43-\mathrm{E}$ & 0.625 & 7.5 & 0.468 & 7.5 & 0.058 \\
\hline $44-1$ & 0.156 & 0.468 & 0.937 & 0.234 & ND \\
\hline $80-1$ & 0.156 & 0.468 & 0.937 & 0.937 & 1.875 \\
\hline $85-2$ & 0.019 & 0.234 & 0.468 & 0.234 & 0.468 \\
\hline $131-1$ & 0.625 & 0.117 & 0.234 & 0.468 & 0.937 \\
\hline $93-2$ & 0.039 & 0.117 & 0.468 & 0.468 & 3.75 \\
\hline $100-1$ & 0.039 & 0.468 & 0.937 & 0.117 & 0.468 \\
\hline $140-1$ & 0.156 & 0.058 & 0.468 & 0.234 & 0.468 \\
\hline $106-1$ & 0.078 & 0.937 & 0.468 & 0.937 & 3.75 \\
\hline $201-1$ & 0.039 & 0.117 & 0.937 & 0.468 & 0.937 \\
\hline 189-1 & 0.078 & 0.234 & 3.75 & 0.234 & 0.937 \\
\hline
\end{tabular}

Cip, ciprofloxacin; T, tetracycline; K, kanamycin; NA, nalidixic acid; C, chloramphenicol.

In vitro antibiotic susceptibility testing of isolates from patients remains an important guide to therapy for clinicians and a useful marker for epidemiological investigations. The adoption of quantitative determinations of antibiotic susceptibility (MIC determination), rather than qualitative methods (i.e., disc diffusion test) may be of importance in identifying small, but potentially clinical significant changes, in antibiotic susceptibility [38]. Interestingly, the study reported a $\mathrm{MIC}_{90}$ range as low as $0.004-7.5 \mu \mathrm{g} / \mathrm{mL}$ with $E$. cloacae being the most susceptible organism and ciprofloxacin the most active antibiotic. The findings support the disc diffusion results in which all the isolates were markedly sensitive to this drug. 


\section{Experimental Section}

\subsection{Bacterial Strains}

A total of $51 \mathrm{~L}$. ivanovii and $33 \mathrm{E}$. cloacae strains were isolated from various food samples which comprised of beef and chicken stew, potatoes, rice, vegetables and pies purchased from cafeterias in Alice. The organisms were isolated and identified as previously reported [39] with some modifications. Briefly, $25 \mathrm{~g}$ of each sample was weighed and homogenized under aseptic conditions in $225 \mathrm{~mL}$ of buffered peptone water. One millilitre of the homogenate was added to a tube containing $9 \mathrm{~mL}$ of sterile buffered peptone water and incubated aerobically at $37{ }^{\circ} \mathrm{C}$ for $12-24$ hours. A loopful of enrichment broth was cultured on Mac Conkey, Eosin-Methylene Blue (EMB) and Colombia blood agar base (Oxoid, Basingstoke, UK) supplemented with 5\% horse blood. The plates were incubated aerobically for $24-48$ hours at $37^{\circ} \mathrm{C}$.

Isolates were presumptively identified based on colony pigmentation, Gram staining characteristics and oxidase test. Small beta hemolytic colonies on Colombia blood agar, Gram-positive short rods and oxidase negative were presumptive of Listeria species while pink colonies on Mac Conkey and metallic sheen colonies on EMB, Gram-negative rods and oxidase negative were presumptive of Enterobacter cloacae. Confirmation of isolates used the API 20E and API Listeria kits (Biomerieux, Marcy-l'Etoile, France). The tests were performed as per manufacturer's instruction for use and data interpretation was performed using the Analytical profile index (API) database (V4.1) with the apiweb $^{\mathrm{TM}}$ identification software.

\subsection{Antibiotic Susceptibility Test}

\subsubsection{Disc Diffusion Test}

Antibiotic susceptibility of the two organisms (L. ivanovii and Enterobacter cloacae) was carried out using disc diffusion method as recommended by the Clinical and Laboratory Standards Institute CLSI [40] on Mueller Hinton agar (Oxoid, Basingstoke,UK) with the following antibiotic discs: ampicillin $(25 \mu \mathrm{g})$, erythromycin $(15 \mu \mathrm{g})$, streptomycin $(25 \mu \mathrm{g})$, chloramphenicol $(30 \mu \mathrm{g})$, ciprofloxacin $(5 \mu \mathrm{g})$, amoxicillin $(20 \mu \mathrm{g})$, nalidixic acid $(30 \mu \mathrm{g})$, tetracycline $(30 \mu \mathrm{g})$, trimethoprim $(5 \mu \mathrm{g})$, vancomycin $(10 \mu \mathrm{g})$, trimethoprim-sulfamethoxazole $(1.25 \mu \mathrm{g})$, gentamicin $(10 \mu \mathrm{g})$, neomycin $(30 \mu \mathrm{g})$, penicillin $\mathrm{G}$ (10 unit), kanamycin $(30 \mu \mathrm{g})$. All discs were obtained from Mast Diagnostics, Merseyside, United Kingdom.

Three to five well-isolated colonies from nutrient agar (Oxoid, Basingstoke, UK) were transferred into $5 \mathrm{~mL}$ normal saline until its turbidity was equivalent to $0.5 \mathrm{McF}$ arland standards. The suspension was streaked uniformly onto Mueller Hinton agar plate with a cotton swab. Antibiotic discs were placed onto the surface of each plate ( 5 antibiotics/petri dish) using a sterile forceps. After incubation at $37{ }^{\circ} \mathrm{C}$ for $24 \mathrm{~h}$, the diameter of growth inhibition zone surrounding each disc was measured and interpreted according to the CLSI [41] recommendation. Currently, there are no interpretative criteria provided by CLSI for Listeria spp. Therefore, the present study used the CLSI criteria for Staphylococci spp. [32]. Staphylococcus aureus NCTC 6571 and Pseudomonas aeruginosa ATCC 15442 reference strains were used to test the efficacy of the discs. 


\subsubsection{Minimum Inhibitory Concentration $\left(\mathrm{MIC}_{90}\right)$ Determination}

Determination of $\mathrm{MIC}_{90}$ was done using the broth-dilution technique as previously described by Nyenje and Ndip [42]. Ciprofloxacin, tetracycline, chloramphenicol, kanamycin and nalidixic acid powders which demonstrated marked susceptibility in the disc diffusion test and available in our laboratory at the time of the experiments were used. Tetracycline, nalidixic acid and chloramphenicol powders were dissolved in $0.2 \%$ DMSO whilst kanamycin and ciprofloxacin were dissolved in sterile distilled water as per manufacturer's instruction.

Mueller Hinton broth $(100 \mu \mathrm{L})$ was dispensed into the wells except the first well of each row which contained $150 \mu \mathrm{L}$ and the last row of wells which contained distilled water. A $50 \mu \mathrm{L}$ of the stock antibiotic was dispensed into the first well; a two-fold serial dilution was carried out up to well number 12 from which $100 \mu \mathrm{L}$ was discarded. Twenty microlitres of standardized bacterial suspension (0.5 McFarland standards) was added to each of the wells except the control wells (control wells contained broth only and distilled water only). An automatic ELISA microplate reader (SynergyMx, Biotek $^{\mathrm{R}}$, Thousand Oaks, CA, USA) adjusted to $570 \mathrm{~nm}$ was used to measure the absorbance of the plates before and after incubation at $37{ }^{\circ} \mathrm{C}$ for 24 hours. The absorbencies were compared to detect an increase or decrease in bacterial growth and the values plotted against concentration. The lowest concentration of the antibiotic resulting in inhibition of $90 \%$ bacterial growth was recorded as the $\mathrm{MIC}_{90}$. The following reference strains Staphylococcus aureus NCTC 6571 and Pseudomonas aeruginosa ATCC 15442 were used as control organisms.

\section{Conclusions}

The results demonstrate the presence of multi-resistant strains of bacteria in ready-to-eat foods. Their public health impact remains unknown, but point to the fact that these foods could be important vehicles transmitting multi-resistant bacteria to humans on a daily basis implying that mitigation of drug resistance in foodborne bacteria is likely to be of benefit to human health.

\section{Acknowledgments}

The authors are thankful to the Govan Mbeki Research and Development Center, University of Fort Hare, South Africa for funding.

\section{Conflict of Interest}

The authors declare no conflict of interest.

\section{References}

1. Collignon, P.; Powers, J.H.; Tom, M.C.; Aidara-Kane, A.; Aarestrup, F.M. World health organization ranking of antimicrobials according to their importance in human medicine: A critical step for developing risk management strategies for the use of antimicrobials in food production animals. Clin. Infect. Dis. 2009, 49,132-141. 
2. Threlfall, E.J.; Ward, L.R.; Frost, J.A.; Willshaw, G.A. The emergence and spread of antibiotic resistance in foodborne bacteria. Int. J. Food Microbiol. 2000, 62, 1-5.

3. Yucel, N.; Citak, S.; Onder, M. Prevalence and antibiotic resistance of Listeria species in meat products in Ankara, Turkey. Food Microbiol. 2005, 22, 241-245.

4. White, D.G.; Zhao, S.; Simjee, S.; Wagner, D.D.; McDermott, P.F. Antimicrobial resistance of foodborne pathogens. Microbes Infect. 2002, 4, 405-412.

5. WHO Fact Sheet 237: Food Safety and Foodborne Illness; 2002. World Health Organization: Geneva, Switzerland. Available online: www.who.int/mediacentre/factsheets/fs237/ (accessed on 12 April 2012).

6. Gashaw, A.; Kassu, A.; Moges, F.; Moges, T.; Kahsay, H. Prevalence of bacteria and intestinal parasites among Food-handlers in Gondar Town, Northwest Ethiopia. J. Health Popul. Nutr. 2008, 26, 451-455.

7. WHO Fact Sheet 237 Reviewed March; 2007. Available online www.who.int/mediacentre/ factsheets/fs237/ (accessed on 5 May 2012).

8. Adak, G.K.; Meakins, S.M.; Yip, H.; Lopman, B.A.; O’Brien, S.J. Disease risks from foods, England and Wales, 1996-2000. Emerg. Infect. Dis. 2005, 11, 365-372.

9. Azziz-Baumgartner, E.; Lindblage, K.; Gieseker, K.; Rogres, H.S.; Kieszak, S.; Njapau, H.; Schleicher, R.; McCoy, L.F.; Misore, A.; DeCock, K.; Rubin, C.; Slutsker, L. Case-control study of an acute aflotoxicosis outbreak, Kenya, 2004. Environ. Health Perspect. 2005, 12, 1779-1782.

10. World Health Organization. Weekly Epidemiological Record; 2006. Available online: http://www.who.int/wer/2006/wer8131.pdf (accessed on 27 August 2012).

11. World Health Organization. Cholera in Zimbabwe; 2009. Available online: http://www.who.int/csr/don/2009_06_09/en/index.html (accessed on 27 August 2012).

12. Mølbak, K. Human health consequences of antimicrobial drug resistant Salmonella and other foodborne pathogens. Clin. Infect. Dis. 2005, 41, 1613-1620.

13. Angulo, F.J.; Nargund, V.N.; Chiller, T.C. Evidence of an association between use of antimicrobial agents in food animals and antimicrobial resistance among bacteria isolated from humans and the human health consequences of such resistance. J. Vet. Med. 2004, 51, 374-379.

14. Guillet, C., Lambert, O.J.; Monnier, A.; Leclerecq, A.; Mechai, F.; Brunnel, M.F.; Scortti, M.; Disson, O.; Berche, P.; Boland, J.V.; et al. Human Listeriosis caused by L. ivanovii. Emerg. Infect. Dis. 2010, 16,136-138.

15. Salihu, M.D.; Junaidu, A.U.; Manga, S.B.; Gulumbe, M.L.A.; Magaji, A.; Ahmed, A.; Adamu, A.Y.; Shittu, A.; Balarabe, I. Occurrence of Listeria monocytogenes in smoked fish in Sokoto, Nigeria. Afri. J. Biotechnol. 2008, 7, 3082-3084.

16. Odjadjare, E.E.O.; Obi, C.L.; Okoh, A.I. Municipal wastewater effluents as a source of listerial pathogens in the aquatic milieu of the Eastern Cape Province of South Africa: A concern of public health importance. Int. J. Environ. Res. Public Health. 2010, 7, 2376-2394.

17. Osaili, T.M.; Alaboudi, A.R.; Nesir, E.A. Prevalance of Listeria spp. and antibiotic susceptibility of Listeria monocytogenes isolated from raw chicken and ready-to-eat chicken products in Jordan. Food Control 2011, 22, 586-590. 
18. Nyenje, M.E.; Odjadjare, C.E.; Tanih, N.F., Green, E.; Ndip, R.N. Foodborne pathogens recovered from ready-to-eat foods from roadside cafeterias and retail outlets in Alice, Eastern Cape Province, South Africa: Public health implications. Int. J. Environ. Res. Public Health. 2012, 9, 2608-2619.

19. Bertrand, S.; Huys, G.; Yde, M.; D’Haene, K.; Tardy, F.; Vrints, M.; Swings, J.; Collard, J.M. Detection and characterization of tet(M) in tetracycline-resistant Listeria strains from human and food-processing origins in Belgium and France. J. Med. Microbiol. 2005, 54, 1151-1156.

20. Allerberger, F.; Wagner, M. Listeriosis: A resurgent foodborne infection. Clinic. Microbiol. Infect. 2010, 16, 16-23.

21. Safdar, A.; Armstrong, D. Antimicrobial activities against 84 Listeria monocytogenes isolates from patients with systemic listeriosis at a Comprehensive cancer centre (1955-1997). J. Clin. Microbiol. 2003, 41, 483-485.

22. Conter, M.; Paludi, D.; Zanardi, E.; Ghidini, S.; Vergara, A.; Ianieri, A. Characterization of antimicrobial resistance of foodborne Listeria monocytogenes. Int. J. Food Microbiol. 2009, 128, 497-500.

23. Charpentier, E.G.; Gerbaud, C.; Jacquet, J.; Courvalin, P. Incidence of antibiotic resistance in Listeria spp. J. Infect. Dis. 1995, 172, 277-281.

24. Srinivasan, V.; Nam, H.M.; Nguyen, L.T.; Tamilselvam, B.; Murinda, S.E.; Oliver, S.P. Prevalence of antimicrobial resistance genes in Listeria monocytogenes isolated from dairy farms. Foodborne Dis. 2005, 2, 201-211.

25. Lund, B.M.; Baird-Parker, T.C.; Gould, G. The Microbiological Safety and Quality of Food; Aspen publisher Inc.: New York, NY, USA, 2000; Volume 2, p. 1399.

26. Krzyminska, S.; Koczura, R.; Mokracka, J.; Puton, T.; Kaznowski, A. Isolates of the Enterobacter cloacae complex induce apoptosis of human intestinal epithelial cells. Microbial. Pathog. 2010, 49, 83-89.

27. Nierop, W.H.; Dese, A.G.; Stewart, R.G.; Bilgeri, Y.R.; Koornhof, H.J. Molecular epidemiology of an outbreak of Enterobacter cloacae in the neonatal intensive care unit of a provincial hospital in Gauteng, South Africa. J. Clin. Microbiol. 1998, 66, 645-649.

28. Brink, A.J.; Coatzee, J.; Clay, C.G.; Sithole, S.; Richards, G.A.; Piorel, L.; Nordmunn, P. Emergence of New Delhi metallo-beta-lactamase (NDM-1) and Klebsiella pneumonia carbapenemase (KPC-2) in South Africa. J. Clin. Microbiol. 2011, 50, 525-527.

29. Mesa, R.J.; Blanc, V.; Blanch, A.R.; Cortés, P.; González, J.J.; Lavilla, S.; Miró, E.; Muniesa, M.; Saco, M.; Tórtola, M.T. Extended-spectrum $\beta$-lactamase-producing Enterobacteriaceae in different environments (humans, food, animal farms and sewage). J. Antimicrob. Chemother. 2006, 58, 211-215.

30. Haryani, Y.; Tunung, R.; Chai, L.C.; Lee, H.Y.; Tang, S.Y.; Son, R. Characterization of Enterobacter cloacae isolated from street foods. ASEAN Food J. 2008, 15, 57-64.

31. Paterson, D.L. Resistance in Gram-negative bacteria: Enterobacteriaceae. Am. J. Infect. Control 2006, 119, S20-S28.

32. Li, Q.; Sherwood, J.S.; Logue, C.M. Antimicrobial resistance of Listeria spp. recovered from processed bison. Lett. Appl. Microbiol. 2007, 44, 86-91. 
33. Chen, B.Y.; Pyla, R.; Kim, T.J.; Silva, J.L.; Jung, Y.S. Antibiotic resistance in Listeria species isolated from catfish fillets and processing environment. Lett. Appl. Microbiol. 2010, 50, 626-632.

34. Arslan, S.; Ozdemir, F. Prevalence and antimicrobial resistance of Listeria spp. in homemade white cheese. Food Control 2008, 19, 360-363.

35. Cornaglia, G.; Hryniewicz, W.; Jarlier, V.; Kahlmeter, G.; Mittermayer, H.; Stratchounski, L.; Baquero, F. European recommendations for antimicrobial resistance surveillance. J. Clin. Microbiol. Infect. 2004, 10, 349-383.

36. Chow, J.W.; Fine, M.J.; Shlaes, D.M. Enterobacter bacteriemia: Clinical features and emergence of antibiotic resistance during therapy. Ann. Inter. Med. 1991, 115, 585-589.

37. DeFrancesco, K.A.; Cobbold, R.N.; Rice, D.H.; Besser, T.E.; Hancock, D.D. Antimicrobial resistance of commensal Escherichia coli from dairy cattle associated with recent multi-resistant salmonellosis outbreaks. Vet. Microbiol. 2004, 98, 55-61.

38. Giovanni, D.B.; Domenico, D.A.; Giovanni, C.; Enzo, B.; Raffaele, P. Comparison of E-test, agar dilution, broth microdilution and disk diffusion methods for testing in vitro activity of levofloxacin against Staphylococcus spp. isolated from neutropenic cancer patients. Int. J. Antimicrob. Agents. 2002, 19, 147-154.

39. Akoachere, J.-F.T.K.; Bughe, R.N.; Oben, B.O.; Ndip, L.M.; Ndip, R.N. Phenotypic characterization of human pathogenic bacteria in fish from the coastal waters of South West Cameroon: Public health implications. Rev. Environ. Health 2009, 24, 147-155.

40. Clinical and Laboratory Standards Institute (CLSI). Performance Standards for Antimicrobial Disk Susceptibility Tests; 9th ed.; Document M2-A9; Clinical and Laboratory Standards Institute (CLSI): Wayne, PA, USA, 2006.

41. Clinical and Laboratory Standards Institute (CLSI). Disk Diffusion Supplemental Tables; Document M100-S17; CLSI: Wayne, PA, USA, 2007.

42. Nyenje, M.E.; Ndip, R.N. In-vitro antimicrobial activity of crude acetone extract of the stem bark of Combretum molle against selected bacterial pathogens. J. Med. Plants Res. 2011, 5, 5315-5320.

(C) 2012 by the authors; licensee MDPI, Basel, Switzerland. This article is an open access article distributed under the terms and conditions of the Creative Commons Attribution license (http://creativecommons.org/licenses/by/3.0/). 